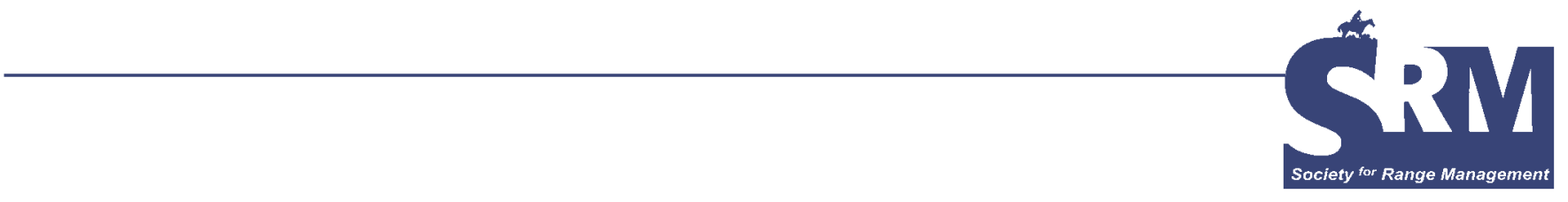

\title{
Selected Essays on Science, Rangelands, and Roles of the Society for Range Management, Volume II
}

\section{By K. M. Havstad}

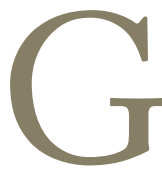

ary Frasier, the editor of Rangelands, took a risk and published a set of 4 of my essays in the December 2005 issue of this magazine. The risk was that these essays were written in an offbeat style, were of a personal and professional nature, bordered on editorial in content, and were overall not the type of writing routinely printed in Rangelands. In addition, I could not point to any prior success in publishing this type of essay. I appreciate that Gary accepted the risk and printed those essays. In my introduction to that set of essays, I commented that these were writings that until having been published had likely been read by only 2 people. Based on feedback I have received since that December publication, those essays have now been read by 4 to 5 times as many people as before. Given that none of the feedback comments on those essays were excessively derogatory or irate rants, Gary felt that he could take an additional risk and publish another set of essays. As before, these remarks are simply my reflections on matters related to our discipline, our profession, and our Society, and meant to serve as threads of conversation.

\section{The Earth is Faster}

I am certainly no expert on the subject of climate change. The amount of individual research on phenomena related to climate change published over the past 20 years is enormous. Even the number of synthesis volumes on the subject is impressive. Yet, it is obviously a subject that cannot be simply dismissed because it is viewed as too complex or too involved. At some point I think it would be easy to simply gravitate to one camp or the other (ie, "the atmosphere is overloaded with anthropogenically produced greenhouse gasses and warming is occurring" camp, or the "earth has experienced these kinds of changes in the past and this is just natural variation" camp) because of personal biases, political beliefs, inherent skepticisms, or unrelated professional agendas (characteristics probably found in either camp). Yet, the subject is deserving of far more detailed treatment, and I have to try and delve into this literature and see if some threads of sense can be identified. Our profession is rooted in trying to understand change, and even in the 19th century scientists suspected that human activities would affect climate (see Kingland's The Evolution of American Ecology, 2005). An essay seemed to be a reasonable motivation to take the plunge into this subject. My written words force me to stare at what I think. Though I'd certainly read related articles that had a bearing on other of my own writings in the past, this was an attempt to more specifically uncover and develop my own sense of understanding. I started with the most current work available - a series of papers published in several issues of Science during the spring of 2006. Here's a brief synopsis:

The serious climate change debate is not centered on whether or not our climate is changing. There is overwhelming evidence of change. The central debate is whether what is being observed is natural variation or an actual new climate, or at least new to us (see Science, 2006, Vol. 311, for numerous and relevant articles). For example, recent reports have documented a warming during winters over the last 30 years of the earth's Antarctic troposphere, the lower portion of the earth's atmosphere from the surface to about 26,000 feet above the South Pole (see Turner et al., Science, 2006, 311:1914). The warming has been $0.5^{\circ}-0.7^{\circ} \mathrm{C}$ per decade, and the authors suspect this is a real change and not an artifact of instrumentation. Yet, they acknowledge that there is tremendous variability in these measures from year to year. They cannot be certain that this is a persistent warming trend. Another example comes from several recently reported observations 
of dramatic increases in the discharges of glaciers tied to polar ice sheets in both the northern and southern hemispheres (see Joughin, Science, 2006, 311:1719; Bindschadler, Science, 2006, 311:1720; Velicogna and Wahr, Science, 2006, 311:1756). These discharges and subsequent glacier changes have been recorded using a variety of methods. They point to warmer conditions, and result in increasing sea levels that would threaten coastal systems. Again, significant, largescale changes are being observed, but the observations are quite variable over time.

There are many, as in very many, examples like this where changes are observed, well quantified, and clearly described. The examples span from the abiotic to the biotic, and from the global scale to the community scale and finer. In many cases, though, causes are not clearly linked to the symptoms, however alarming. In most cases a set of possibilities are typically described, often linked to the present level of atmospheric carbon dioxide of 380 parts per million, up from the preindustrial level of the 19th century of 290 parts per million. But uncertainty of cause and effect is prevalent in these reports.

All of this quantitative climate change evidence is both stunning and overwhelming, and it is being published in the top scientific journals in the world. Yet, there is another type of evidence that strikes close to home with our profession. To a great extent our discipline relies on an ability to understand the history of a landscape, to understand how its legacies are manifested in its current structure and dynamic. Much of our management technology is based on an interpretation of where a landscape has been and how it has evolved to its present state. The best range managers are those that are able to "read" the land. This ability also has a history of importance in the climate change debate. For example, it is well recognized that the El Nino phenomena (unusual warming every 2-7 years of ocean currents flowing south from the equator along the coast of South America) were first recognized by native fisherman. The very active field of research on $\mathrm{El}$ Nino events has its roots in human observations of complex phenomena tracked over generations.

In 2002 the Arctic Research Consortium of the United States published a book entitled The Earth is Faster Now. The title comes from observations by people indigenous to the Arctic Circle that they could no longer make predictions about the weather. Their typical indicators did not work anymore, and weather patterns were changing faster than what the knowledge built up over generations of observations had taught them. The earth, or its collective processes that were important to people living on the edge of land and in direct contact with the margins most sensitive to change, was, in their words, "moving faster." The collective senses of their environment built up over generations, which have a direct bearing on their survival, were telling them that the climate is different, and different than just natural variations. Those are powerful and persuasive observations. Though these are not the type of observations that are typically accepted for publi- cation in our top journals, these are powerful and persuasive observations to those who believe in the validity of personal interpretations of our environment, especially over generations. These environmental interpretations deserve strong consideration in this debate.

Our climate is changing. We are faced with the choices to mitigate and/or adapt. The truth is, we know ways to mitigate, but appear to lack the global resolve. Interestingly, our profession is based on employing skills to adapt to dynamic, harsh environments as our science has a history of addressing key issues associated with adaptation. Who has an active research community reporting on data sets related to coping with drought, contending with shifting vegetation structure and composition, plant responses to elevated $\mathrm{CO}_{2}$, and vegetation relationships to water yields? See the March 2006 issue of Rangeland Ecology \& Management for examples. The earth may be "moving faster," but our science is working to maintain its relevance for informing adaptation of policies and management in response to those changes.

\section{Oysters}

Joe Fortes Seafood and Chop House is just a few blocks from the 2 main hotels that hosted the SRM annual meeting in Vancouver this past February. Finding this establishment during the week of the meeting was a combination of luck and fate. Fortes offers a menu that matches its name, serves a number of regional beers complimented by a contemporary wine list, and is best known for its selections of the many local, seasonal oysters served shucked or pan seared. I think I should have just gone ahead and forwarded a pay check directly there to cover my tab. Actually, there were multiple tabs that exceeded any per diem because I took up occupancy in Fortes as a home away from home over a 7-day period. I could use the feeble excuse that my home town of Las Cruces is a long way from good fresh seafood, both in distance with its landlocked geography and in time because it has been tens of millions of years since shallow oceans covered the northern Chihuahuan Desert. In reality, though, it was the proximity, the company, the libations, and the oysters. As one who shies away from larger functions like receiving lines leading to convention banquets, the bar stools and dining tables at Joe Fortes provided the perfect compliment to the meeting rooms and hotel hallways of the convention. Though my following recollections of these outings may be a bit distorted for a variety of reasons, they capture their spirit and the inherent values of creating a time each year where we can sit down together and talk.

Early in the week it was a group of 8 for a very civilized Sunday brunch that included talk about science, recent federal agency activities in the District of Columbia, the financial status of SRM, food, local art, and champagne. It was a fitting way to initiate our convention-related discussions. On another occasion it was lunch with the SRM board members that started with talk about anything but board activities, but eventually wandered into reflections on the success 
of our new executive vice president and the high quality of the SRM headquarters staff. Following the opening plenary session, a science colleague and I retreated to bar stools and reflected on the wonderful remarks delivered earlier that Monday morning by the Honorable Iona Campanola, the Lieutenant Governor of the Province of British Columbia. We discussed who in US politics could give a similar highquality, self-drafted speech. The resulting list was short, and we agreed that the next set of board members need to work on this issue. Another evening it was sitting at the oyster bar with a colleague from Oregon and talking about science directions in our agency, finding new ways to build local support for rangeland research programs, the state of our 2 main SRM publications, beer, and clam chowder. Given that it was Valentine's Day and we were surrounded by urbane couples, he correctly commented that I was the worst looking date in the place. We've been friends for a long enough time that leads to friendly jabs, but my retort was concurrence. I should have had him pick up the tab. On a different occasion it was a late session after late meetings that led to talk of politics and career directions, and beer, and trying not to look too out of place downtown in a city and its surrounding area of 2 million people. Given that I had been nearly living at Fortes I'm afraid I looked like I fit in by then. Another outing followed the excellent day-long special session on Chinese grasslands made more memorable with Jianguo Wu's critique of David Tilman's hypotheses on species diversity and productivity. This after-hours session was with 2 close friends and talk drifted to the mini tempest arising around the proposed changes to our academic accreditation standards, beer, oysters, of course, and China. We recognized that outside of North America we need to find ways to better engage the international community in SRM. Fortunately, people within the Society already have some ideas on how to do this, and we are starting to act on those ideas.

On my last night in Vancouver we retreated to Fortes after a very enjoyable Thursday afternoon technical session involving 5 colleagues and myself critiquing results from decades of grazing systems research. That grazing systems session was one of my meeting highlights, not that we entirely satisfied the audience, but because we had engaged ourselves and fellow professionals, and that was certainly my main goal. But the wait to be seated at Fortes was going to be too long and we had to resort to another nearby establishment. I recalled Yogi Berra's classic quip about a nightclub in New York-no one went there anymore because it was too crowded.

Probably between one-fourth and one-third of our total membership attended the Vancouver meeting. It was a highly successful event, and the Pacific Northwest Section working in concert with Ann Harris and our Headquarters staff did a tremendous job in organizing and hosting this convention. I'm not sure how many other attendees I saw in Joe Fortes restaurant at one time or another, but it was quite a few. In Reno next year I may have to gravitate towards an establishment serving Rocky Mountain oysters. I know I will still drift away from the larger banquet-type gatherings. But the meetings are all about engaging in conversations, no matter how that is done. I will still find a place to sit down with friends and discuss events of the day and enjoy the fact that I belong to this profession and our Society, the subjects and debates it encompasses, and the people it attracts.

\section{Cheese}

A symposium critiquing the history of grazing system research findings held during the 2006 Annual Society for Range Management meeting in Vancouver upset some people. Some in the audience felt that the collective analyses of the speakers were biased, excessively controversial, needlessly provocative, and/or harmful to the profession of grazing management. I was one of 8 symposium participants (speakers and their coauthors), and I cannot disagree too strongly with this overall impression. My intent was certainly to explain my biases, offer discussion points that would encourage debate and controversy, and provoke in a professional manner. Never, though, was the intent to harm the profession. In the aftermath of this symposium there has been some discussion about responsibilities of speakers to consider the influence of their words, and possibly filter their remarks if they could be misconstrued and misinterpreted resulting in unintended consequences. Certainly, it is important to remember and recognize the powers inherent in the spoken and written word. However, beyond a reminder of that potential power, I think I have an obligation to avoid tempering my remarks for the following 3 reasons:

\section{Who is to say what is appropriate?}

In October 2004 I was invited to Croatia, Bosnia and Herzegovina to speak at an international conference on rangeland management. The conference was held in Mostar, a city in this area of the former Yugoslavia that saw some of the worst fighting 10-12 years earlier during the Bosnian War. Tens of thousands had been massacred, the centuries-old bridge over the Neretva River splitting the city of Mostar had been destroyed, and the war had global repercussions only now receding with Slobodan Milosovic's death. In walking to the convention center from my hotel I passed graveyards where the expanse of headstones all carried the same dates in 1994. Buildings were still rubble in certain sections of the city. The Old Bridge had been rebuilt, though, and this meeting was one of the region's first forays into bringing the outside world back into this part of Herzegovina. At noon of the first day of the conference they had a side activity where local cheese producers had brought their products in for judging. These were sheep cheeses aged inside skins, a local, traditional product they were trying to market more broadly across $\mathrm{Eu}-$ rope. Their national television was on site to broadcast the event, including the subsequent awards ceremony. Though I was not involved in the judging, I was asked to sit in front as a US Department of Agriculture (USDA) official while winners were announced. There was a good crowd as they began 
the ceremony, though I have no sense of the "ratings" for the television broadcast. Near the end of the event, as they were nearly ready to announce a grand winner, they named a third place award. The farmer stood, in the black leather jacket classic to the eastern European style of dress, and protested loudly. While he spoke the person next to me learned over and translated for me. He said the farmer was announcing to his local and television audience that his cheese was better than third place and he was not going to accept this award. He was pretty upset. This was important to him, and he was going to speak his mind. I couldn't help it, but I started to laugh. Not a big attention getting kind of laugh, but one that was a product of the situation as I perceived it. Here we were just a few years from a country torn apart by war, religious hatred, fear, and lack of leadership. The graves were right outside. Maybe someone with State Department training would have remained stoic. But, for me, I thought this was a great example of how far they had come from that prior devastation, and I wouldn't have realized that progress without hearing his comments. I think it was a laugh of some relief. I'd like to think that in 10 years I could sit in some town in Iraq and hear someone complain about the results of a cheese judging contest. Maybe as a USDA representative I should not have found the situation that amusing. But I know that I could explain my behavior to satisfy my own sense of what is appropriate and responsible. That is the only measuring stick I can consistently use.

\section{I can only speak and write from my own perspectives.}

Earlier this year I wrote an essay entitled "Oysters" (included in this set of essays) about my reflections on our 2006 annual SRM meeting. Those reflections were accumulated while hanging out after hours in a restaurant in Vancouver that specializes in oysters. For me, this essay is about conversations, and the importance of conversation with friends and colleagues. Yet, I realize the essay does focus on the bar elements of this restaurant at times, and drinking beer and wine depending upon the meal. It is quite possible that some members will perceive this as an essay about drinking. The truth is, I leave those essays to Hunter Thompson's legacy because I could never write from that level of depravity. I realized, though, as I hit the send button in submitting this essay to the publisher, that I ran the risk of that perception, and that some might hold me in a lower esteem (if that is possible) after reading this essay. Yet, it would have been false for me to filter this perception out of the essay. It reflects who I am, and conveys my perception about what I think is important. All I can hope is that if someone arrives at a different perception about what I have spoken or written that they speak or write to me or someone who does know me for further clarification. Maybe the responsibility for perceptions is also shared by the listener or the reader.

\section{We have to critique to advance.}

I work in Las Cruces with a wonderful group of people. We are basically on the same pages, and we have a fairly decent understanding of each other and where we are headed. It is a congenial group of professionals. Yet, for us to really move forward, to really advance our ideas and our science, I know that we have to be able to thoroughly critique each other's ideas. This is our next big hurdle as a group. We have to have professionally tougher skins, and be able to be frank and direct with each other. In this fashion we will make sure we are putting forward our best ideas. It is not easy, and sometimes I weaken. Yet, upon reflection I know that I need to push this standard of behavior. Now is not the time to weaken, irrespective of what position we might hold in a professional nonprofit organization of 3,500 members. There just aren't enough of us to have some of us back off.

None of the above reasons fall back to the standard rationale that we all have the right, as has often been said, to say either incredibly stupid (see above text) or incredibly smart things (to be written, I trust). What these reasons speak to is that even if we are misunderstood, what is important is that we offer our perspectives, that we push the envelope of our understanding of our environment and our place in it, and that we work to further instill in this Society a culture of conversation without filters. We need to stand up and tell people what we think about our own cheese.

Author is Supervisory Scientist, US Department of Agriculture, Agricultural Research Service, Jornada Experimental Range, MSC 3JER, NMSU, PO Box 30003, Las Cruces, NM 88003, khavstad@nmsu.edu. 